\title{
Timing of Immigration Effects Asset Change Among Hispanic Caregivers of Older Family Members
}

\author{
Tamara Cadet ${ }^{1,2}$ (I) Shanna L. Burke ${ }^{3}$ (1) $\cdot$ Frances Nedjat-Haiem ${ }^{4} \cdot$ Louanne Bakk $^{5} \cdot$ Mitra Naseh $^{3}$. \\ Adrienne Grudzien ${ }^{3}$. Janice O'Driscoll ${ }^{3} \cdot$ Amary Alcide $^{3}$
}

Accepted: 25 September 2020 / Published online: 6 October 2020

(c) Springer Science+Business Media, LLC, part of Springer Nature 2020

\begin{abstract}
Given the cultural value of family in Hispanic culture, older Hispanic immigrants are likely to have family caregivers. This study examined the economic implications of caring for older Hispanic adults regarding non-housing financial wealth over time. Using the 2008, 2010, and 2012 waves of the Health and Retirement Study (HRS) and RAND HRS data files, this study compares changes in the non-housing financial wealth between 2008 and 2012 by caregiving and immigration status among Hispanics. This study examined differences in assets between Hispanic caregivers and non-caregivers and more specifically examined the subpopulation of Hispanic caregivers who immigrated prior to and after 1968 as compared to U.S.-born caregivers to better understand the effect of the Immigration and Nationality Amendment Act of 1965 on asset change. Results indicate that caregiving itself did not have a statistically significant association with wealth, but the timing of immigration to the US had a statistically significant correlation $(p<.05)$ with changes in the financial wealth. The findings of this study have implications for policy and program development targeting older adults and caregiving for this population.
\end{abstract}

Keywords Informal care-giving $\cdot$ Cross-cultural studies $\cdot$ Economics $\cdot$ Latino/a $\cdot$ Mexican American $\cdot$ Relocation and transition $\cdot$ Hispanic $\cdot$ Immigration

Family caregiving for older adults has increasingly become a national conversation partly due to the economic impact of caregiving. With the continuing growth in the older adult population in the US, the need for caregivers is expected to rise as older adults experience physical and health challenges as they continue to age (Koller et al. 2014).Previous research has estimated that $39 \%$ of adults 18 years or older are family caregivers in some capacity (The Pew Research Center for People and the Press 2013). Furthermore, many

Tamara Cadet

tamara.cadet@simmons.edu

1 School of Social Work, Simmons University, 300 The Fenway, Boston, MA 02115, USA

2 Harvard School of Dental Medicine, Oral Health Policy and Epidemiology, Boston, MA, USA

3 Robert Stempel College of Public Health and Social Work, Florida International University, Miami, FL, USA

4 School of Social Work, San Diego State University, San Diego, CA, USA

5 The University at Buffalo, Buffalo, NY, USA family caregivers care for individuals that are 75 or older with high burden chronic illnesses (The National Alliance for Caregiving [NAC] and AARP Public Policy Institute 2015). According to the National Academies Report (2016), family caregivers provide an enormous share of long-term services and supports to older adults. The rising cost of caregiving services has influenced the costs of affordable paid caregiving, leading to the use of unpaid or informal caregiving support within families. Additionally, many families experience loss of income through job loss and have lower financial wealth while providing care as paid caregiving services become less affordable, especially for older adults with significant long-term care needs, which is also seen among older Hispanic adults, as they can deplete all available financial resources (e.g., including vehicles, businesses, and real estate except residential) within 2 years of needed caregiving services (Johnson and Wang 2019). The financial burden of paid caregiving services on older adults suggests that the oldest and sickest are least likely to have enough income to pay for services. Therefore, non-paid, informal caregiving becomes the norm for many families with lower financial wealth. 
Family caregiving can be examined within the context of informal caregiving, which is when an individual provides unpaid and regular assistance with activities of daily living or instrumental activities to those with chronic illnesses or disabilities (Roth et al. 2015a, b). The decision to care for a family member is due to various factors, including the willingness of potential caregivers to provide care, care recipients' needs, financial needs, and perceptions and attitudes towards formal care (McCann and Evans 2002; Pinquart and Sörensen 2011). Findings from Birtha and Holms (2017) indicated that emotional bonds (57\%), sense of duty (15\%), and a personal sense of obligation (13\%) were among factors to provide informal care.

Despite the reasons for providing informal care, much of the caregiving literature focuses on caregiver burden and stress in part because of increased levels of disability of care recipients, increased hours of care needed, changes in caregiving tasks that are more demanding, sex, and age of the caregiver (Metzelthin et al. 2017; Sibalija et al. 2018; Wajnberg et al. 2016; Wang and Wu 2018). Findings from a systematic review of caregiving (Plöthner et al. 2019) suggest that there is a need for respite care for caregivers. Further, some of the caregiver burden and stress is also related to changing economic status. Specifically, the National Academies report (2016) noted that many family caregivers of older adults report moderate to high levels of financial strain and those most at risk of financial problems include those who are caring for highneed adults, are low income or have limited resources, and reside with the care recipient.

When considering racial and ethnical minority caregivers, empirical evidence indicates that minority caregivers have a lower socioeconomic status, are more likely to live with their care recipients, utilize informal networks for care, and often express more positive attitudes towards caregiving than non-Hispanic Whites (Pinquart and Sörensen 2005; Rote and Moon 2018; Roth et al. 2015a, b). These positive attitudes may in part be due to the cultural orientations that suggest that caregiving networks may be more supportive for minority caregivers (Clay et al. 2008). These cultural orientations may be of particular importance for minority immigrants. Rote and Moon (2018) noted that the following factors shape immigration caregiving: language barriers, discrimination in health care settings, and a lack of socioeconomic resources to get access to formal services (Mukadam et al. 2011; Neufeld et al. 2002; Silverstein and Wang 2015; Treas and Mazumdar 2002). It is notable that immigrants who relocate to the US come with existing social and family ties that may be small, thus increasing the likelihood of caregiving responsibilities (Angel et al. 2014; Viruell-Fuentes and Schulz 2009).

\section{Hispanics and Caregiving}

Evidence indicates that Hispanic caregivers account for a significant number of total caregivers in the US. Specifically, $21 \%$ of all Hispanic individuals are caregivers, which equates to approximately 7.6 million individuals (NAC and AARP Public Policy Institute 2015). Therefore, caregiving is particularly important for vulnerable aging Hispanic populations as they have previously experienced barriers to health access, limited health insurance, inadequate management of chronic medical conditions, and poor health outcomes when sick. Hispanic immigrants often underutilize health care services and tend to receive poor quality of services when care is provided (Ortega et al. 2015). Hispanics families also underutilize formal systems of social support services for older adults in need of caregiving because of cultural beliefs and values that view caregiving as a family responsibility, which is often known as "familism" (Flores et al. 2009; Gelman 2014). Socioeconomic issues contribute to gaps in caregiving for Hispanic families caring for their older adults in need. Other factors that influence barriers in Hispanic family caregiving include fear of being discriminated against when asking for assistance, language barriers that make it more difficult to understand how to access services, and lack of knowledge regarding available resources which contributes to underutilization of social services (Valle et al. 2004).

\section{Hispanics and Economic Impacts of Caregiving}

Higher demand for caregivers of older adults may result in low-cost methods of care such as informal or unpaid homecare (Feinberg et al. 2011), which is often welcomed by Hispanic families (Carrion and Nedjat-Haiem 2013). In general, financial resources to support caregivers remain limited, exacerbating the stressors caregivers face (Gardiner et al. 2014; Smith et al. 2002). According to the NAC and AARP Public Policy Institute report (2015), close to half of the caregivers in the US earn less than $\$ 50,000$ per year and around $60 \%$ have not received a high school or postsecondary degree. Based on this report, approximately $20 \%$ of caregivers experience some form of financial stress caused by providing care (NAC and AARP Public Policy Institute 2015). These economic stressors may stem from factors such as a reduction in work hours, leaving careers to attend to care responsibilities, care needs that are not covered by health insurance plans, relocating and/or remodeling a home due to care requirements, and 
augmenting personal financial priorities to newly realized requirements of care (Brazil et al. 2010; MetLife Mature Market Institute 2011; NAC and AARP Public Policy Institute 2015; Smith et al. 2010). It is estimated that for family caregivers over the age of 50, aggregate wage lost can amount to over $\$ 300,000$ due to workforce absence and loss of Social Security benefits and pension funds (MetLife Mature Market Institute 2011).

Hispanic caregivers may be more financially impacted than non-Hispanic White caregivers due to a variety of factors, including lower education levels and lower household incomes. For example, 24\% of Hispanic caregivers lack a high school diploma compared to $5 \%$ of non-Hispanic Whites (NAC and AARP Public Policy Institute 2015). Further, only $13 \%$ of Hispanic caregivers have completed a college education compared to $20 \%$ of non-Hispanic Whites and $14 \%$ of African Americans (NAC and AARP Public Policy Institute 2015). Sixty-one percent of Hispanic caregivers earn a household income of less than $\$ 50,000$ per year (NAC and AARP Public Policy Institute 2015). This occurs despite the fact that Hispanic caregivers are more likely to be employed outside the home while providing care than other ethnic groups (NAC and AARP Public Policy Institute 2015). These educational and employment obstructions, coupled with linguistic limitations and other cultural barriers, may further complicate the experience of family caregiving among the Hispanic population (Cafferty et al. 2002; Ramos et al. 2010; Scharlach et al. 2008).

\section{Hispanics and Immigration}

Projections indicate that by 2050, Hispanics will account for 20\% of all Americans aged 65 and older (Vincent and Velkoff 2010). The increase in the older Hispanic population can be attributed in part to immigration. According to the Population Reference Bureau (2013), the older immigrant population in the US has increased by $70 \%$ since 1990. Despite experiencing challenges of immigration and socioeconomic disadvantages such as lack of education, some Hispanic immigrant groups tend to have longer life expectancies compared to non-Hispanic Whites (Angel 2009). Due to immigration challenges and less favorable socioeconomic characteristics, as older adults, Hispanic immigrants are likely to have higher rates of chronic conditions and functional limitations than U.S.-born Hispanics and nonHispanic Whites (Angel 2009; Angel et al. 2014). These patterns increase the likelihood that older Hispanics will need caregivers. Additionally, given the importance of family as a significant cultural value among Hispanics, caregiving is expected within the Hispanic culture and among Hispanic families, regardless of migration and increased acculturation over time in the US (Velásquez et al. 2004).

\section{The Immigration and Nationality Amendments Act of 1965}

The historical context of U.S. immigration policy directly impacts caregiving across generations of Hispanic families, particularly from an economic lens. The Immigration and Nationality Amendments Act of 1965 established a preference system for immigration based on family reunification, allowing immigration of family members for U.S. citizens already living in the US (Kandel 2018). Enacted in 1968, this legislation gave immigration priority to relatives of U.S. citizens and those with needed employment skills (Potocky and Naseh 2019). Therefore, this policy enhanced the possibility that multiple generations of Hispanic families could live together or in close proximity within the country (Center for Immigration Studies 1995). Consequently, Hispanic older adults could have their immediate family members come to the US to help them as caregivers. However, evidence suggests that this legislation may have attracted individuals with limited skills and low economic contributions in the family reunion process (Yeo 2013). Thus, caregivers were coming to the US as permitted by family reunification and due to factors associated with social exclusion and human capital theories in addition to aging parents, became caregivers.

Despite the evidence that indicates the financial strain that exists for caregivers in general and specifically for caregivers of Hispanics, there is less understanding of the financial impact that emerges with the provision of informal care when the role of immigration is considered. Given national conversations about immigration and its effects, the goal of this study was to better understand the economic status of Hispanic caregivers relative to their immigration status. Exploring potential benefits and obstacles specific to Hispanic caregivers will better inform future policy and practice decisions.

\section{Purpose of the Study}

To better understand the financial impact of informal caregiving in the Hispanic population, the primary aim of this study was to investigate the financial wealth differences (measured by the sum of non-housing financial wealth such as stock, checking accounts, savings accounts, and bonds) between three groups of caregivers: (1) Hispanic caregivers who immigrated to the US prior to 1968 , (2) Hispanic caregivers who immigrated to the US after 1968, and (3) U.S.-born Hispanic caregivers. The year 1968 is used as a benchmark to divide those migrating before and after the Immigration and Nationality Act of 1965, which 
was enacted in 1968 (Marinari 2014). To date, little to no research has been conducted to study differences in asset change among Hispanic caregivers relative to their immigration status and the 1965 Immigration and Nationality Amendment Act (sec. 79 Stat. 911, 1965). The secondary aim of the study was to examine financial wealth differences between Hispanic caregivers and non-caregivers.

\section{Conceptual Framework}

The conceptual framework of this study is grounded in social exclusion and human capital theories. Both theories explain associated factors related to economic disadvantages (Bäckman and Nilsson 2011; Laderchi et al. 2003). Social exclusion is considered a process where individuals or populations are unable to fully participate in society as a result of factors such as unemployment, low skill level, poverty, and poor health. Thus, social exclusion is a multidimensional concept that suggests that the lack of resources in employment, education, health, and housing can be both interrelated and mutually reinforcing (Bäckman and Nilsson 2011). Social exclusion theory suggests a relationship between social exclusion and deprivations among individuals and groups. Specifically, social exclusion theory originates from two theories, one which stresses resources (Townsend 1979) and the other stresses labor market exclusion (Jahoda and Zeisel 2002) such that factors such as financial poverty and unemployment are causal factors related to social exclusion. However, Bäckman and Nilsson (2011) suggest that unemployment and financial poverty should be considered as dimensions of social exclusion. Further, they suggest that being unemployed leads to an inability to have a certain type of social relations that comes with employment and an inability to participate in the labor market-a social institution. Financial poverty is similar in that those with financial poverty are unable to access a social activity such as consumption of goods and resources. The exclusion that results from unemployment and financial poverty is the most important indicator of social exclusion (Burchard 2000).

The human capital theory is a theory of earnings (McKernan and Ratcliffe 2002). Earnings are considered one of the major determinants of poverty. The theory posits that individuals make decisions to invest in human capital such as education and training and this impacts their lifetime earnings. Varying levels of investment in education and training are explained by the individuals' expected returns from the investment. Thus, individuals who expect to be compensated by higher lifetime earnings will choose to invest. Therefore, individuals who expect to work less in the labor market and have few work opportunities such as members of ethnic minorities, are less likely to invest in human capital. As a result, members of ethnic minority groups may earn less and may be more likely to be poor (McKernan and Ratcliffe 2002).

Given the unemployment and financial poverty that Hispanic caregivers may experience due to lack of education and training and their expectations of working less and having fewer work opportunities (Dimov and Shepherd 2005; Laderchi et al. 2003), the study hypothesis posits that there would be a difference in asset change between Hispanic caregivers and non-caregivers, assuming that caregivers could face higher levels of social exclusion and lower levels of human capital; and that there would be a difference in asset change among Hispanic caregivers who immigrated to the US before and after 1968 and those who were born in the country. This hypothesis assumes that the possibility of immigration to the US through family reunion allows caregivers with lower human capital levels to immigrate to the country. Thus, to understand the influence of the Immigration and Nationality Amendment Act of 1965 on Hispanic caregivers and their economic status, this study also relies upon key constructs of Bandura's Social Cognitive Theory (SCT; Bandura 1986).

The framework of SCT suggests there is an interaction between an individual, their environment, and their behaviors. The emphasis is on the influences in an individuals' environment, both external and internal, and how the influences affect them. Specifically, the SCT framework explains the way individuals acquire and maintain a behavior such as financial wealth while considering the social environment in which the individual participates. Thus, the premise of this study, utilizing SCT, is that caregivers' financial wealth is the result of the interaction between personal factors and environmental factors. Personal factors affecting financial wealth were operationalized as age, biological sex, marital status, health status, language, poverty status, and educational level. Environmental factors were operationalized as the Immigration and Nationality Amendment Act of 1965, caregiver, and immigration status. The study hypothesis posits that the Immigration and Nationality Amendment Act of 1965 would have an effect on caregiving.

\section{Design and Methods}

\section{Study Design and Sample}

This study utilizes secondary data from the 2008, 2010, and 2012 waves of the Health and Retirement Study (HRS) and RAND HRS data files to examine changes in caregivers' economic situation over time (RAND Center for the Study of Aging 2013). Primarily funded through the National Institute on Aging (NIA U01AG009740), the HRS is designed, administered, and conducted by the Institute for Social Research at the University of Michigan. The HRS is 
a nationally representative population study of more than 20,000 Americans over the age of 50 designed to assess the relationship between health and retirement (Juster and Suzman 1995). To be included in this study, respondents were required to (1) identify as Hispanic; (2) respond to the questions that asked about providing financial assistance to parents; (3) respond to the questions that asked about U.S. citizenship, and (4) respond to the questions regarding the year of immigration to the US. The final analytic sample of this study consisted of 493 respondents. This study received Institutional Review Board approval from Simmons University and Florida International University.

\section{Measures}

The outcome variable of this study was non-housing financial wealth based on the social exclusion and human capital theories. The independent variables were caregiver status and immigration status, the environmental factors of the SCT, and the control variables were age, biological sex, marital status, health status, language, poverty status, and educational level, the personal factors of SCT.

\section{Non-housing Financial Wealth}

Non-housing financial wealth was the primary outcome measure of interest and obtained from the RAND Income and Wealth Imputation File. This longitudinal file contains imputations and summary measures for all income and wealth variables derived from the HRS. In this study, we used a single measure to indicate non-housing financial wealth, which could be affected by financial strains in a short period of time, between 2008 and 2012. Non-housing financial wealth was calculated as the sum of all household stock, checking accounts, savings accounts, certificates of deposit, bonds, and other assets considering the household debt. This imputed measure did not include the value of individual retirement accounts, Keogh plans, or the value of any real estate, vehicles, or businesses.

\section{Caregiver Status}

Caregiver status was measured using three questions in the HRS that asked respondents if they: (1) gave financial assistance to their parents; (2) helped their parents with personal needs; or (3) helped their parents with errands. From these questions, a dichotomous variable was constructed to indicate caregiver status. If the respondent indicated they engaged in any of the three caregiving behaviors in the past 2 years, they were coded as 1 and considered a caregiver, otherwise, they were coded as 0 .

\section{Immigration Status}

Immigration status was assessed using two questions in the HRS that asked respondents: (1) whether they were born in the US and (2) the year they immigrated to the US. A variable was created that categorized the respondents into three groups: born in the US, immigrated before 1968, and immigrated in or after 1968. Moreover, a dichotomous variable was defined to separate those who immigrated in or after 1968 (coded 1) from those who immigrated before 1968 (coded 0). Immigration year was a continuous variable ranging from 1913 to 2012.

\section{Control Variables}

We controlled for biological sex (male versus female), age (in years), marital status (married versus not married), selfreported health (excellent to poor), number of chronic health conditions (high blood pressure, diabetes, cancer, lung disease, heart disease, stroke, psychiatric problems, and arthritis), poverty status (living above poverty versus below poverty), and years of education in our analyses. Also, a single measure that indicated whether the HRS was administered in Spanish versus English was included.

\section{Analytic Strategy}

First, descriptive statistical analysis was applied to explore the sociodemographic characteristics of the sample (Table 1). Moreover, to determine the bivariate association between respondent sociodemographic characteristics and caregiver status, the Pearson's chi-square test was used to compare proportional differences, and the Wald test was used to compare mean differences (Table 1).

A differences-in-differences approach was used to compare non-housing financial wealth between Hispanics who were caregivers and Hispanics who were non-caregivers. The Wald test was used to examine the way these two groups differed in 2008 versus 2010 and 2008 versus 2012, while accounting for the complex sampling design of the HRS including stratification, clustering, and oversampling of minority groups (Table 2). Mixed regression was conducted to evaluate whether the passage of time had a differential impact on non-housing financial wealth (Table 3). The model included caregiver status (with non-caregiver as the reference group), time indicator, and the interaction term between these two variables. The coefficient of caregiver status estimates differences in non-housing financial wealth between caregivers and non-caregivers. The time indicator assesses changes in non-housing financial wealth in 2008 through 2012. The interaction term is the parameter of interest. This showed how the difference in an outcome measure (e.g., non-housing financial wealth) between non-caregivers 
Table 1 Characteristics of Hispanic respondents by caregiver status, 2008 Health and Retirement Study

\begin{tabular}{|c|c|c|c|c|}
\hline Characteristic & $\begin{array}{l}\text { Total } \\
n=493\end{array}$ & $\begin{array}{l}\text { Caregiver } \\
\mathrm{n}=212\end{array}$ & $\begin{array}{l}\text { Not a caregiver } \\
\mathrm{n}=281\end{array}$ & $p$ \\
\hline \multicolumn{5}{|l|}{ Gender $(\%)^{1}$} \\
\hline Male & 46.2 & 47.6 & 45.1 & \multirow[t]{2}{*}{0.6753} \\
\hline Female & 53.8 & 52.4 & 54.9 & \\
\hline Mean age $(\mathrm{SD})^{1}$ & $59.3(7.2)$ & $59.2(7.7)$ & $59.4(6.8)$ & 0.7344 \\
\hline \multicolumn{5}{|l|}{ Marital status $(\%)^{1}$} \\
\hline Married & 73.7 & 74.6 & 73.0 & \multirow[t]{2}{*}{0.7225} \\
\hline Not married & 26.3 & 25.4 & 27.0 & \\
\hline \multicolumn{5}{|l|}{ Self-reported health $(\%)^{1}$} \\
\hline Excellent & 9.4 & 9.9 & 9.1 & \multirow[t]{5}{*}{$<.05$} \\
\hline Very good & 19.4 & 22.1 & 17.2 & \\
\hline Good & 32.1 & 27.9 & 35.3 & \\
\hline Fair & 28.2 & 33.3 & 24.3 & \\
\hline Poor & 10.9 & 6.8 & 14.1 & \\
\hline Mean number of health conditions (SD) ${ }^{1}$ & $1.5(1.3)$ & $1.3(1.2)$ & $1.8(1.5)$ & $<.001$ \\
\hline \multicolumn{5}{|l|}{ Living in poverty $(\%)^{1}$} \\
\hline Yes & 84.2 & 11.7 & 19.1 & \multirow[t]{2}{*}{$<.05$} \\
\hline No & 15.8 & 88.3 & 80.9 & \\
\hline Mean years of education $(\mathrm{SD})^{1}$ & $10.1(4.6)$ & $10.3(4.5)$ & $10.1(4.6)$ & 0.6698 \\
\hline \multicolumn{5}{|l|}{ Language $(\%)^{1}$} \\
\hline Spanish & 41.6 & 47.5 & 37.0 & \multirow[t]{2}{*}{$<.05$} \\
\hline English & 58.4 & 52.5 & 63.0 & \\
\hline \multicolumn{5}{|l|}{ Immigration status $^{1}$} \\
\hline U.S. born & 50.8 & 43.4 & 56.5 & \multirow[t]{3}{*}{$<.01$} \\
\hline Immigrated before 1968 & 12.9 & 11.7 & 13.8 & \\
\hline Immigrated in or after 1968 & 36.6 & 44.9 & 29.7 & \\
\hline
\end{tabular}

${ }^{1}$ Weighted $\%$ and mean
Table 2 Non-housing financial wealth among Hispanic caregivers and non-caregivers in 2008, 2010, and 2012

\begin{tabular}{llll}
\hline Caregiver status & \multicolumn{2}{l}{ Mean wealth $^{1}$} & \\
\cline { 2 - 4 } & 2008 & 2010 & 2012 \\
\hline Caregiver & 31,189 & 37,672 & 64,135 \\
Non-caregiver & 20,367 & 31,831 & 17,291 \\
\hline
\end{tabular}

To test the statistical significance of difference in mean wealth between 2008 and 2010, and 2008 and 2012, the Wald test for continuous variables was used

${ }^{1}$ Weighted mean

and caregivers changed over time or between 2008 and 2012 when controlling for biological sex, age, marital and health status, poverty, education, and language. If the coefficient for the interaction between the caregiver status variable and time indicator is negative and significant, non-housing financial wealth among caregivers declined at a significantly larger rate over time than that among non-caregivers. If the coefficient for the interaction between the caregiver status variable and time indicator is positive and significant, non-housing
Table 3 Adjusted mixed regression results for non-housing financial wealth in 2008-2012 among Hispanics, by caregiver status $(n=493)$

\begin{tabular}{llr}
\hline & Coefficient & \multicolumn{1}{c}{ SE } \\
\hline Non-caregiver (Reference) & & \\
Caregiver & $-11,998$ & 12,361 \\
Year & -2810 & 3982 \\
Caregiver $\times$ year & 8246 & 5841 \\
Wald $\chi^{2}$ (df) & $43.20(14)$ & \\
\hline
\end{tabular}

Mixed regression analyses were adjusted for gender, age, marital status, self-reported health, chronic health conditions, poverty status, education, and language

$S E$ standard error

financial wealth among caregivers increased at a significantly larger rate over time than that among non-caregivers.

Mixed regression was also conducted to examine changes in non-housing financial wealth among caregivers who immigrated before 1968 , in or after 1968, and respondents who were born in the US (Table 4). This model included immigration status (with U.S.-born as the reference group), time indicator, and the interaction terms between these 
Table 4 Adjusted mixed regression results for non-housing financial wealth in 2008-2012 among Hispanic caregivers, by immigration status $(\mathrm{n}=291)$

\begin{tabular}{llr}
\hline & Coefficient & SE \\
\hline U.S. born (Reference) & & \\
Immigrated before 1968 & $-44,900$ & 37,636 \\
Immigrated in or after 1968 & 7506 & 26,445 \\
Year & 7043 & 7571 \\
Immigrated before 1968 $\times$ year & 25,548 & 16,460 \\
Immigrated in or after 1968 $\times$ year & -8711 & 10,057 \\
Wald $\chi^{2}(\mathrm{df})$ & $32.84(16)$ & \\
\hline
\end{tabular}

Mixed regression analyses were adjusted for gender, age, marital status, self-reported health, chronic health conditions, poverty status, education, and language

$S E$ standard error

Table 5 Adjusted mixed regression results for wealth in 2008-2012 among Hispanic caregivers, by immigration year $(n=169)$

\begin{tabular}{lll}
\hline & Coefficient & SE \\
\hline Immigrated before 1968 (Reference) & & \\
Immigrated in or after 1968 & 55,916 & 38,522 \\
Year & $33,737 *$ & 14,574 \\
Immigrated in or after 1968 × year & $-36,170^{*}$ & 15,748 \\
Wald $\chi^{2}(\mathrm{df})$ & $13.45(14)$ & \\
\hline
\end{tabular}

Mixed regression analyses were adjusted for gender, age, marital status, self-reported health, chronic health conditions, poverty status, education, and language

$S E$ standard error

$* P<.05$

variables. We also explored whether the passage of time had a differential impact on non-housing financial wealth when comparing respondents immigrating to the US in or after 1968 to respondents immigrating before 1968 (Table 5). This model included immigration year (with immigrating to the US before 1968 as the reference group), time indicator, and the interaction term between two variables.

All analyses were performed in Stata version 14 (StataCorp 2015). The HRS and RAND provide panel data in a wide format in which observations were the respondents, and the variables were their characteristics (caregiver status, immigration status, biological sex, age, marital status, selfreported health, chronic health conditions, poverty status, education, and language) at each time point. Commands for regression analyses in Stata version 14 require that the panel data be in long format. To rearrange the data, the "reshape" command was used. This command converted the data from wide to long format. Using this approach, the observations were the respondents at each point in time and the variables were the observed characteristics (Kohler and Kreuter
2012). The "reshape" command also created a new variable for 'time,' which was coded as 1 for 2008, 2 for 2010, and 3 for 2012.

Survey commands were used to account for the complex sampling design (stratification and clustering) of the HRS when computing standard errors for calculated estimates. The HRS sampling weights were applied to adjust for sample selection probability or oversampling of select minority groups and interviewee nonresponse and to obtain estimates that reflect the general population. Significance in all analyses was tested at the $p<.05$ level.

\section{Results}

\section{Descriptive Statistics}

Around half of the sample (Hispanic respondents) was female and this distribution was similar among the caregivers and non-caregivers. The mean age of the sample was around 59 and similar among caregivers and non-caregivers. The majority of the sample (around 74\%) and the majority of caregivers and non-caregivers were married. Caregivers were more likely to self-report better health conditions $(p<.05)$ and fewer health problems $(p<.001)$. When considering poverty status, a larger proportion of non-caregivers had an annual income below the Federal Poverty Level (19\%) compared to caregivers (12\%). With regard to language, a larger proportion of caregivers had the HRS administered in Spanish (48\%) compared to non-caregivers (37\%). Caregivers were less likely $(p<.01)$ to be a U.S.-born and more likely to enter the country in or after 1968 compared to non-caregivers (Table 1).

The mean non-housing financial wealth was higher among caregivers than non-caregivers in 2008, 2010, and 2012. Though non-housing financial wealth did not significantly change between 2008 and 2010 for either of these two groups, non-caregivers had a reduction between 2008 and 2012 while caregivers had an increase over this period of time. Mean financial wealth decreased from $\$ 20,367$ to $\$ 17,291$ between 2008 and 2012 among non-caregivers and increased from $\$ 31,189$ to $\$ 64,135$ among caregivers within that same period (Table 2).

\section{Multivariate Analysis Results}

Results of the adjusted mixed regressions showed that changes in the non-housing financial wealth (from 2008 to 2012) did not have a statistically significant association $(p>0.5)$ with the caregiving status (Table 3$)$. Similarly, changes in the non-housing financial wealth (from 2008 to 2012) did not have a statistically significant association $(p>0.5)$ with the immigration status (Table 4). However, 
changes in the non-housing financial wealth (from 2008 to 2012) had a statistically significant $(p<0.5)$ association with the immigration year, before 1968 versus in or after 1968 (Table 5). Relative to caregivers immigrating to the US before 1968, caregivers immigrating in or after 1968 had a significantly greater decrease in non-housing financial wealth between 2008 and $2012(p<.05)$.

\section{Discussion}

Utilizing the conceptual framework of this study, we first examine differences in assets between Hispanic caregivers and non-caregivers, and subsequently examine the subpopulation of Hispanic caregivers who immigrated prior to and after 1968 and U.S.-born caregivers to better understand the economic changes that are reported to occur for caregivers in each of those three conditions. The first hypothesis was not supported. The act of caregiving itself did not affect assets over time, which is contrary to the assumption that Hispanic caregivers may experience higher levels of social exclusion and lower levels of human capital. However, the timing of immigration did. Perhaps this change was buffered by the communal aspect of Hispanic caregiving, given that evidence in the literature that at least one other unpaid family or friend assists in caretaking responsibilities for Hispanics (Evercare and NAC 2008) which can be interpreted as an environmental factor from the SCT framework. Overall, findings from this study indicate that Hispanic caregivers who immigrated after 1968 (compared to those who immigrated prior to 1968) reported a greater decrease in assets over time $(p<.05)$, after controlling for relevant covariates. Adjusted models did not indicate differences between the caregivers and non-caregivers, and Hispanic immigrant caregivers and U.S.-born caregivers.

We hypothesized that the Immigration and Nationality Amendment Act of 1965 would have an effect on caregiving as an environmental factor from the SCT framework. Among the provisions of the Immigration and Nationality Amendment Act of 1965, was the preference system, which gave priority to immigrants who had relatives who were U.S. citizens. Therefore, a result of the Act was that a greater percentage of families would likely live together or within close proximity to one another supporting the cultural tradition of caregiving. Based on our findings, there was a difference between those who immigrated before or after 1968 when the Amendment of the Act was implemented. Those who immigrated after 1968 reported a greater decrease in assets over time. Interestingly, those who immigrated prior to 1968 were more likely to have financially viable skills since that was a requirement of immigration policy. Those who immigrated after 1968 may have had skills however, the Act exempted family members from the skills requirement indicating that those who immigrated after 1968 may have had reduced levels of human capital and financially viable skills supporting findings of this study. Further, based on the literature, immigrant caregivers who are less acculturated and less educated are less likely to accept outside resources compared to more acculturated immigrant caregivers. Therefore, based on the social exclusion theory a decrease in assets would be expected (Friedemann et al. 2013). Furthermore, this phenomenon directly relates to the strain of familial financial resources and the abilities of adult children to provide care for their older adult family members who were the original immigrants from before the Immigration and Nationality Amendment Act of 1965 (Carrion and Nedjat-Haiem 2013).

Furthermore, empirical research indicates that $20 \%$ of older Hispanic adults live in poverty (National Hispanic Council on Aging 2012). This finding can possibly explain that additional family members may be draining or saturating the already limited financial resources. In addition, previous research (Evercare and NAC 2008) suggests that caregiving negatively affects assets through a decreased likelihood of working outside the home in order to care for parents or spouses. As the intensity of care needed increases, the reduced hours or likelihood to work outside the home decreases. For caregivers who have left the formal employment sector to provide care, there is a compounded effect where these individuals see a smaller growth in their assets, and a higher risk of meeting the threshold for poverty (Butrica and Karamcheva 2014). Additionally, empirical research (National Hispanic Council on Aging 2012) suggests that many older adult immigrants are unable to participate in programs such as Supplemental Security Income (SSI) or Supplemental Nutrition Assistance Program (SNAP) due to criteria, which includes becoming a naturalized citizen or demonstrating a work history. This may explain the decrease in assets for immigrants after 1968 because they may be unable to supplement their income in a significant way.

Interestingly, findings indicate that there was not a significant difference in assets between Hispanic caregivers and non-caregivers over time. Older Hispanics on average have lower assets compared to non-Hispanic Whites (National Hispanic Council on Aging 2012). Therefore, one would expect the Hispanic caregiver would have less, given the evidence that indicates that older Hispanic adults have fewer financial resources. This is despite the results in this study which suggest that caregivers actually have more assets than non-caregivers. Although this study did not distinguish between types of care recipients (spouse or parents), it is widely reported that caregivers of parents tend to be in a better financial position (less debt and higher assets) than non-caregivers (Wolff et al. 2016). A caregiver, for instance, is reported to have net assets of $\$ 142,300$, while 
the non-caregiver has $\$ 120,000$. This suggests that those who are in a better financial position are more likely to take care of their parents. This dynamic is disrupted, however, when taking into account caregiving for spouses. Caring for a spouse has a greater effect on asset change than caregiving for a parent. Spousal caregivers are more likely to meet poverty thresholds, are less likely to own a home, and, on average, have $\$ 15,000$ less in earnings per year as compared to those who are caring for a parent. Perhaps the sample of caregivers in this study indirectly reflects the findings in the literature that suggest that caregiving is a planned role in the Hispanic culture (Carrion and Nedjat-Haiem 2013). Therefore, caregiving is expected, planned for, and potentially shared between family members. This would suggest that we would not see a difference between caregivers and non-caregivers.

There are several limitations to the study reported herein, including the use of secondary data, which does not precisely address the variables utilized. Assets, which often refer to property holdings, may not reflect a holistic financial situation for some adults. For instance, cash on hand might be more relevant to some families. Given the previous literature and the variables available for analysis, the focus here was on assets, though future studies may extend to more fluid measures of wealth and stability. In addition, there were other areas where we were limited by secondary analysis in that we utilized the data that best-represented caregiving. There is other information that would have also helped to create a more comprehensive view of caregiving including the onset and duration of caregiving and the extent of caregiver burden. Other limitations include other possible variables that may interact with immigration status before or after 1968 such as age at immigration and level of acculturation, which was not available in the HRS dataset. Furthermore, several immigration policies have been enacted since 1968 that could have impacted the family structure among Hispanics in the US, however, the Immigration and Nationality Amendment Act of 1965 remained the cornerstone for immigration through family reunification.

\section{Conclusions and Implications}

From a policy perspective, it is important to consider the context of a wider national debate as baby boomers prepare for retirement and take a realistic approach to the economic costs of this period of life. Inflation and the rising age of social security benefits have often obscured discussions about unpaid and informal caregiving costs, but projected increases in minority aging adult populations, especially among the advanced aging (85+) who have the highest rates of need and disability (He and Luke 2014), make informal caregiving a relevant, timely and necessary part of the national conversation. Lack of formal support and programs to assist and reimburse caregivers elevates their risk of decreasing assets such that they meet the poverty threshold and experience smaller growth in assets over time. Equally important is the ongoing national debate about immigration and the limitations of resources available and in some cases intentionally not provided that can affect older immigrants and their caregivers. Specifically, at the time of this writing this paper, the world is facing a global coronavirus pandemic and the US appears to have approximately $33 \%$ of the cases and $28 \%$ of the deaths, (Centers for Disease Control 2020). There have been resources provided to some US citizens. However, the recently funded CARES Act specifically excludes undocumented immigrants and the 8 million citizens living with an undocumented family member (Duncan and Horton 2020). Further, with the job loss and increasing numbers of unemployed, it is likely that those caregivers are the individuals who are part of the gig economy and who may or may not be able to collect unemployment insurance. This affects the finances of immigrant family members and those caring for their older family members. Finally, creating continued awareness and implementation of the recently passed legislation, Raise Family Caregiver Act may help caregivers' economic situations (National Hispanic Council on Aging 2017).

Findings from this empirically-based investigation indicate the importance of not only seeking to provide or increase services and resources for caregivers but to specifically consider the cultural differences that may exist among Hispanic caregivers, which are similar to recommendations from other investigations (Radina and Barber 2004). This includes how this cultural group may differ from caregivers of other cultural groups, as well as considering how these caregivers may be different from each other, despite the common ethnic umbrella term. Utilizing this information is critical for policy and program development designed to target older Hispanics for available and needed benefits. If available benefits can increase older Hispanics' economic security, the overall U.S. economy can be expected to grow (National Council on Aging 2012). Perhaps, there is a need to collaborate with Hispanic organizations to develop programs and services to meet the needs of Hispanic caregivers as described in this study.

Funding This study did not receive funding.

\section{Compliance with Ethical Standards}

Conflict of interest The authors declare that they have no conflict of interest.

Research Involving Human and Animal Rights While this research did not include human participants because it was a secondary data analy- 
sis, institutional review approval was received by the primary author's institution.

Informed Consent Because this study was a secondary data analysis, informed consent was not necessary.

\section{References}

1965 Immigration and Nationality Act, a.k.a. the Hart-Cellar Act (An Act to amend the Immigration and Nationality Act, and for other purposes). Pub. L. No. 89-236, § 79 Stat. 911, 2580 H. R. 911 (1965).

Angel, J. L., Rote, S. M., Brown, D. C., Angel, R. J., \& Markides, K. S. (2014). Nativity status and sources of care assistance among elderly Mexican-origin adults. Journal of Cross-Cultural Gerontology, 29(3), 243-258. https://doi.org/10.1007/s1082 3-014-9234-9.

Angel, R. J. (2009). Structural and cultural factors in successful aging among older Hispanics. Family \& Community Health, 32(10), S46. https://doi.org/10.1097/01.FCH.0000342839.05607.2a.

Bäckman, O., \& Nilsson, A. (2011). Pathways to social exclusion-A life-course study. European Sociological Review, 27(1), 107-123. https://doi.org/10.1093/esr/jcp064.

Bandura, A. (1986). Social foundations of thought and action: A social cognitive theory. Englewood Cliffs, NJ: Prentice Hall.

Birtha, M., \& Holm, K. (2017). WHO CARES? Study on the challenges and needs of family carers in Europe. Brussels: COFACE.

Brazil, K., Bainbridge, D., \& Rodriguez, C. (2010). The stress process in palliative cancer care: A qualitative study on informal caregiving and its implication for the delivery of care. American Journal of Hospice and Palliative Medicine, 27(2), 111-116. https://doi. org/10.1177/1049909109350176.

Burchard, T. (2000). Social exclusion: Concepts and evidence. In D. Gordon \& P. Townsend (Eds.), Breadline Europe. The measurement of poverty (pp. 385-405). Bristol: Policy press.

Butrica, B., \& Karamcheva, N. (2014). The Impact of Informal Caregiving on Older Adults' Labor Supply and Economic Resources: Final Report. Retrieved from https://www.dol.gov/sites/default/ files/ebsa/researchers/analysis/retirement/the-impact-of-informalcaregiving-on-older-adults-labor-supply-and-economic-resources. pdf.

Cafferty, P. S., Engstrom, D. W., \& Roderick, M. (2002). Hispanics and education. In P. S. Cafferty \& D. W. Engstrom (Eds.), Hispanics in the United States (pp. 1-29). Retrieved from https://www.trans actionpub.com/title/978-1-56000-415-8.html.

Carrion, I. V., \& Nedjat-Haiem, F. R. (2013). Caregiving for older Latinos at end of life: Perspectives from paid and family (unpaid) caregivers. The American Journal of Hospice \& Palliative Care, 30(2), 183-191. https://doi.org/10.1177/1049909112448227.

Centers for Disease Control and Prevention. (2020). Cases in the US. Retrieved from https://www.cdc.gov/coronavirus/2019-ncov/cases -updates/cases-in-us.html.

Center for Immigration Studies. (1995). Three Decades of Mass Immigration: The Legacy of the 1965 Immigration Act. Retrieved from Center for Immigration Studies website: https://cis.org/1965I mmigrationAct-MassImmigration.

Clay, O. J., Roth, D. L., Wadley, V. G., \& Haley, W. E. (2008). Changes in social support and their impact on psychosocial outcome over a 5-year period for African American and White dementia caregivers. International Journal of Geriatric Psychiatry, 23(8), 857-862.

Dimov, D. P., \& Shepherd, D. A. (2005). Human capital theory and venture capital firms: Exploring "home runs" and "strike outs". Journal of Business Venturing, 20(1), 1-21. https://doi. org/10.1016/j.jbusvent.2003.12.007.

Duncan, W. L., \& Horton, S. B. (2020). Serious challenges and potential solutions for immigrant health during COVID-19. Retrieved from https://www.healthaffairs.org/do/10.1377/hblog20200 416.887086/full/. https://doi.org/10.1377/hblog20200416.88708 6/full/.

Evercare, \& NAC. (2008). Evercare study of Hispanic family caregiving in the U.S.: Findings from a national study. Retrieved from https://www.caregiving.org/data/Hispanic_Caregiver_Study _web_ENG_FINAL_11_04_08.pdf.

Feinberg, L., Reinhard, S. C., Houser, A., \& Choula, R. (2011). Valuing the invaluable: 2011 update, the growing contributions and costs of family caregiving. Washington, DC: AARP Public Policy Institute, 32, 2011.

Friedemann, M.-L., Buckwalter, K. C., Newman, F. L., \& Mauro, A. C. (2013). Patterns of caregiving of Cuban, other Hispanic, Caribbean Black, and White Elders in South Florida. Journal of CrossCultural Gerontology, 28(2), 137-152. https://doi.org/10.1007/ s10823-013-9193-6.

Flores, Y. G., Hinton, L., Barker, J. C., Franz, C. E., \& Velasquez, A. (2009). Beyond familism: A case study of the ethics of care of a Latina caregiver of an elderly parent with dementia. Health Care for Women International, 30(12), 1055-1072.

Gardiner, C., Brereton, L., Frey, R., Wilkinson-Meyers, L., \& Gott, M. (2014). Exploring the financial impact of caring for family members receiving palliative and end-of-life care: A systematic review of the literature. Palliative Medicine, 28(5), 375-390.

Gelman, C. R. (2014). Familismo and its impact on the family caregiving of Latinos with Alzheimer's disease: A complex narrative. Research on Aging, 36(1), 40-71.

He, W. \& Luke J. L. (2014). Older Americans With a Disability: 2008-2012. U.S. Census Bureau, American Community Survey Reports.

Jahoda, M., \& Zeisel, H. (2002). Marienthal: The sociography of an unemployed community. Piscataway, NJ: Transaction Publishers.

Johnson, R. W., \& Wang, C. X. (2019). The financial burden of paid home care on older adults: Oldest and sickest are least likely to have enough income. Health Affairs, 38(6), 994-1002.

Juster, F. T., \& Suzman, R. (1995). An overview of the Health and Retirement Study. The Journal of Human Resources, 30, S7-S56.

Kandel, W. A. (2018). U.S. Family-Based Immigration Policy. Retrieved from https://fas.org/sgp/crs/homesec/R43145.pdf.

Kohler, U., \& Kreuter, F. (2012). Data analysis using stata, third edition (3rd ed.). Retrieved from https://www.stata.com/bookstore/ data-analysis-using-stata/.

Koller, D., Schön, G., Schäfer, I., Glaeske, G., van den Bussche, H., \& Hansen, H. (2014). Multimorbidity and long-term care dependency-A five-year follow-up. BMC Geriatrics, 14(1), 70.

Laderchi, C. R., Saith, R., \& Stewart, F. (2003). Does it matter that we do not agree on the definition of poverty? A comparison of four approaches. Oxford Development Studies, 31(3), 243-274. https ://doi.org/10.1080/1360081032000111698.

Marinari, M. (2014). Americans Must Show Justice in Immigration Policies Too: The Passage of the 1965 Immigration Act. Journal of Policy History, 26(02), 219-245. https://doi.org/10.1017/S0898 030614000049.

McCann, S., \& Evans, D. S. (2002). Informal care: The views of people receiving care. Health \& Social Care in the Community, 10(4), 221-228.

McKernan, S. M., \& Ratcliffe, C. E. (2002). Transition events in the dynamics of poverty. The Urban Institute, September. Retreived from http://webarchive.urban.org/publications/410575.html.

MetLife Mature Market Institute. (2011). The Met Life study of caregiving costs to working caregivers: Double Jeopardy for Baby Boomers caring for their parents. Retrieved from https://www. 
caregiving.org/wp-content/uploads/2011/06/mmi-caregiving -costs-working-caregivers.pdf.

Metzelthin, S. F., Verbakel, E., Veenstra, M. Y., Van Exel, J., Ambergen, A. W., \& Kempen, G. I. (2017). Positive and negative outcomes of informal caregiving at home and in institutionalised long-term care: A cross-sectional study. BMC Geriatrics, 17(1), 232.

Mukadam, N., Cooper, C., \& Livingston, G. (2011). A systematic review of ethnicity and pathways to care in dementia. International Journal of Geriatric Psychiatry, 26(1), 12-20.

National Academies of Sciences, Engineering, and Medicine. (2016). Families caring for an aging America. Washington, DC: National Academies Press.

National Alliance for Caregiving \& AARP Public Policy Institute. (2015). Caregiving in the U.S., 2015 Report. Retrieved from https://www.caregiving.org/wp-content/uploads/2015/05/2015_ CaregivingintheUS_Final-Report-June-4_WEB.pdf.

National Hispanic Council on Aging. (2012). State of Hispanic Older Adults: An Analysis and Highlights from the Field (pp. 23-37). Retrieved from National Hispanic Council on Aging website: https://www.nhcoa.org/wp-content/uploads/2012/10/State-ofHispanic-Older-Adults-Brief-2012-.pdf.

National Hispanic Council on Aging. (2017). 2017 Status of Hispanic older adults: Insights from the field-Caregivers edition. Washington, DC: National Hispanic Council on Aging: 2017.

Neufeld, A., Harrison, M. J., Stewart, M. J., Hughes, K. D., \& Spitzer, D. (2002). Immigrant women: Making connections to community resources for support in family caregiving. Qualitative Health Research, 12(6), 751-768.

Ortega, A. N., Rodriguez, H. P., \& Vargas Bustamante, A. (2015). Policy dilemmas in Latino health care and implementation of the Affordable Care Act. Annual Review of Public Health, 36, 525-544.

Pinquart, M., \& Sörensen, S. (2005). Ethnic differences in stressors, resources, and psychological outcomes of family caregiving: A meta-analysis. The Gerontologist, 45(1), 90-106.

Pinquart, M., \& Sörensen, S. (2011). Spouses, adult children, and children-in-law as caregivers of older adults: A meta-analytic comparison. Psychology and Aging, 26(1), 1.

Plöthner, M., Schmidt, K., De Jong, L., Zeidler, J., \& Damm, K. (2019). Needs and preferences of informal caregivers regarding outpatient care for the elderly: A systematic literature review. BMC Geriatrics, 19(1), 82.

Population Reference Bureau. (2013). Elderly Immigrants in the United States. Retrieved April 27, 2019, from https://www.prb. org/us-elderly-immigrants/.

Potocky, M., \& Naseh, M. (2019). Best practices for social work with refugees and immigrants (2nd ed.). New York: Columbia University Press.

Radina, M., \& Barber, C. E. (2004). Utilization of formal support services among Hispanic Americans caring for aging parents. Journal of Gerontological Social Work, 43(2-3), 5-23. https:// doi.org/10.1300/J083v43n02_02.

Ramos, B. M., Jurkowski, J., Gonzalez, B. A., \& Lawrence, C. (2010). Latina women: Health and healthcare disparities. Social Work in Public Health, 25(3), 258-271.

RAND Center for the Study of Aging. (2013). RAND HRS Data Documentation. Retrieved from RAND website: https://hrson line.isr.umich.edu/index.php?p=showdesc.

Rote, S. M., \& Moon, H. (2018). Racial/ethnic differences in caregiving frequency: Does immigrant status matter? The Journals of Gerontology: Series B, 73(6), 1088-1098.

Roth, D. L., Dilworth-Anderson, P., Huang, J., Gross, A. L., \& Gitlin, L. N. (2015a). Positive aspects of family caregiving for dementia: Differential item functioning by race. Journals of
Gerontology Series B: Psychological Sciences and Social Sciences, 70(6), 813-819.

Roth, D. L., Fredman, L., \& Haley, W. E. (2015b). Informal caregiving and its impact on health: A reappraisal from population-based studies. The Gerontologist, 55(2), 309-319.

Scharlach, A. E., Giunta, N., Chow, J. C.-C., \& Lehning, A. (2008). Racial and ethnic variations in caregiver service use. Journal of Aging and Health, 20(3), 326-346. https://doi.org/10.1177/08982 64308315426.

Sibalija, J., Savundranayagam, M. Y., Orange, J. B., \& Kloseck, M. (2018). Social support, social participation, \& depression among caregivers and non-caregivers in Canada: A population health perspective. Aging \& Mental Health, 24(5), 765-773. https://doi. org/10.1080/13607863.2018.1544223.

Silverstein, M., \& Wang, R. (2015). Does familism inhibit demand for long-term care? Public policy implications of growing ethnic diversity in the United States. Public Policy \& Aging Report, 25(3), 83-87.

Smith, C. E., Pace, K., Kochinda, C., Kleinbeck, S., Koehler, J., \& Popkess-Vawter, S. (2002). Caregiving Effectiveness Model evolution to a midrange theory of home care: A process for critique and replication. Advances in Nursing Science, 25(1), 50-64.

Smith, C., Piamjariyakul, U., Yadrich, D. M., Ross, V. M., Gajewski, B., \& Williams, A. R. (2010). Complex home care: Part IIIEconomic impact on family caregiver quality of life and patients' clinical outcomes. Nursing Economics, 28(6), 393-399, 414.

StataCorp. (2015). Stata Statistical Software: Release 14. Retrieved from https://www.stata.com/new-in-stata/.

The Pew Research Center for People and the Press. (2013). Family Caregivers. Retrieved from https://www.pewinternet.org/2013/06/20/ family-caregivers/.

Treas, J., \& Mazumdar, S. (2002). Older people in America's immigrant families: Dilemmas of dependence, integration, and isolation. Journal of Aging Studies, 16(3), 243-258.

Townsend, P. (1979). Poverty in the United Kingdom: A survey of household resources and standards of living. Harmondsworth, Middlesex, England: Univ of California Press.

Valle, R., Yamada, A. M., \& Barrio, C. (2004). Ethnic differences in social network help-seeking strategies among Latino and EuroAmerican dementia caregivers. Aging \& Mental Health, 8(6), 535-543.

Velásquez, R., Arellano, L. M., \& McNeill, B. (Eds.). (2004). The handbook of Chicanalo psychology and mental health. Mahwah, NJ: Lawrence Erlbaum.

Vincent, G. K., \& Velkoff, V. A. (2010). The next four decades: The older population in the United States: 2010 to 2050. U.S. Department of Commerce, Economics and Statistics Administration, U.S. Census Bureau, 25-1138.

Viruell-Fuentes, E. A., \& Schulz, A. J. (2009). Toward a dynamic conceptualization of social ties and context: Implications for understanding immigrant and Latino health. American Journal of Public Health, 99(12), 2167-2175.

Wajnberg, A., Soones, T. N., Smith, K. L., Russell, D., Ross, J. S., \& Federman, A. (2016). Identifying sociodemographic characteristics associated with burden among caregivers of the urban homebound: The importance of racial and relationship differences. Gerontology and Geriatric Medicine, 2, 2333721416667878.

Wang, M. S., \& Wu, C. F. (2018). Assisting caregivers with frail elderly in alleviating financial hardships. Social Work in Public Health, 33(6), 396-406.

Wolff, J. L., Spillman, B. C., Freedman, V., \& Kasper, J. D. (2016). A National Profile of Family and Unpaid Caregivers Who Assist Older Adults with Health Care Activities. Retrieved September 13, 2016, from Urban Institute website: https://www.urban.org/ research/publication/national-profile-family-and-unpaid-careg ivers-who-assist-older-adults-health-care-activities. 
Yeo, Y. (2013). How Welfare Reform Act Affects Elderly Immigrants' Health and Healthcare Service Utilization: Comparisons Before and After Welfare Reform. (Doctoral dissertation). Retrieved from https://scholarcommons.sc.edu/etd/1916.

Publisher's Note Springer Nature remains neutral with regard to jurisdictional claims in published maps and institutional affiliations.
Tamara Cadet is faculty at Simmons University School of Social Work and also holds a faculty appointment at the Harvard School of Dental Medicine. Dr. Cadet is currently funded by the National Institute on Aging and the Health Resources and Services Administration. She has also been funded by the National Cancer Institute. Her research interests include evidence-based health promotion interventions to increase health equity among vulnerable populations. 